\title{
Isolation of the Culture of Fungal Mycelium from Glowing Wood
}

\author{
Alexey P. Puzyr*, \\ Svetlana E. Medvedeva and Vladimir S. Bondar \\ Institute of Biophysics SB RAS \\ 50/50 Akademgorodok, Krasnoyarsk, 660036, Russia
}

Received 07.05.2016, received in revised form 21.06.2016, accepted 14.08.2016

Pure mycelial culture of glowing mushroom is usually obtained from the fruiting body of the fungus or basidiospores. Attempts to obtain pure cultures from glowing pieces of wood, leaf litter or soil are not always successful. This paper describes the study of glowing wood samples which were collected on the Island Borneo in November and December 2013. A method to isolate mycelium culture of glowing mushroom from the collected samples is proposed. Control of the luminescence and selection of the samples is performed for the first time with the system of video documentation, which can record the image of studied object and its luminescence. The moisture maintenance of the studied sample is the most important condition for obtaining a pure culture of glowing mycelium. Fast transportation to the laboratory and sterile conditions are not so obligatory for solving this problem. The obtained pure culture of glowing mycelium is registered in the Culture Collection of Institute of Biophysics SB RAS with the number IBSO 2371. It can be used for a wide variety of in vivo and in vitro studies, including the identification of the fungus. When grown on solid media, the mycelium has long-lasting bright luminescence, the level and duration of which depends on the composition of the medium used. Distinctive features of the studied culture are as follows: (a) the presence of local areas of the mycelium that change the intensity of the luminescence for short periods (several minutes) when it grown on solid media or natural wood; (b) the absence of bioluminescence in submerged culture. After incubation of the culture in deionized water the pellets of the mycelium change the level of luminescence under action of external factors (mechanical stimulation, the addition of different substances - hydrogen peroxide, NADPH, extract from the fruiting bodies Pholiota squarrosa).

Keywords: bioluminescence, luminous fungus, light emitting wood, culture of luminous mycelia.

DOI: $10.17516 / 1997-1389-2016-9-3-304-320$.

(C) Siberian Federal University. All rights reserved

* Corresponding author E-mail address: apuzyr@mail.ru 


\title{
Выделение культуры грибного мицелия \\ из светящейся древесины
}

\author{
А.П. Пузырь, С.Е. Медведева, В.С. Бондарь \\ Институт биофизики СО РАН \\ Россия, 660036, Красноярск, Академгородок, 50/50
}

В статье описан способ выделения культуры светящегося грибного мицелия из образцов светящейся древесины, обнаруженных на острове Борнео в ноябре-декабре $201320 д а$. Контроль свечения и отбор светящихся образцов впервые проводили с помощью системь видеодокументации. Показано, что для успешного выделения культуры светящегося грибного мицелия из обнаруженных в лесу образцов светящейся древесины обязательным условием является сохранение их влажности; не столь важна их быстрая транспортировка в лабораторию и соблюдение стерильных условий. При выращивании на твердых питательных средах полученный мицелий характеризуется низкой скоростью роста, длительньм временем свечения, появлением и исчезновением локальных областей с высоким уровнем люминесценции. При культивировании гриба в условиях погруженной культуры свечение мицелия не регистрируется, что, вероятно, связано с отсутствием или крайне мальм содержанием в биомассе субстрата люминесиентной реакции. Полученная чистая культура светящегося мицелия зарегистрирована в Коллекции культур Института биофизики СО РАН под номером ИБСО 2371 и может быть использована для широкого спектра исследований in vivo и in vitro, включая идентификацию гриба.

Ключевые слова: биолюминесиенщчия, светящчиеся грибы, светоизлучающая древесина, культура светящегося мицелия.

\section{Введение}

Исследования биолюминесценции высших грибов (базидиомицетов), как правило, начинаются с обнаружения в ночном лесу светящихся плодовых тел, мицелиальные изоляты которых потом поддерживаются в коллекциях. Морфологические характеристики плодового тела (из которого получен изолят) позволяют определить таксономическое положение изучаемого базидиомицета и проводить в лабораторных условиях исследования биолюминесценции мицелия известного гриба. Однако существует несколько исключений из этого правила, когда исследуется люминесценция мицелия светящихся грибов на естественном древесном субстрате при отсутствии плодовых тел.

В частности, А.А. Ячевский в своей книге, вышедшей в 1933 году (Ячевский, 1933), писал, что Л. Тюлан в 1898 году и Х. Молиш в 1904 году отмечали свечение опавших листьев различных лиственных деревьев (например, бука, клена, дуба), лежащих на лесной почве целыми пластами. Обычно эти листья покрыты и пронизаны белой паутинистой грибницей, не образующей плодовых тел. Было сделано предположение, что грибница относится к родам Anthina Fries или Himantia Fr. либо входит в цикл развития видов рода Marasmius. Важно упоминание о том, что 
Х. Молиш наблюдал свечение такой грибницы в чистой культуре. Следовательно, еще в 1904 году была продемонстрирована возможность роста мицелия люминесцентного гриба в лабораторных условиях на искусственных питательных средах при отсутствии плодовых тел.

Во второй половине прошлого века авторы работы (Sabharwal et al., 1983) описали характеристики светового излучения в естественных условиях для образцов древесины деревьев, собранных в Индии, которые светятся во время периода муссонов. Авторы считали, что это новая биолюминесцентная система грибов из образцов древесины с характерным максимумом излучения $518 \pm 1$ нм. Было показано, что вода важна для люминесценции и от нее зависит кинетика реакции. Авторы планировали продолжать исследования, однако дальнейших работ не появилось.

В сравнительно недавней работе (Deheyn, Latz, 2007) сообщалось, что куски дерева с мицелием грибов, собранные ночью между 20 января и 7 февраля 2005 года в тропических лесах Бокас дель Торо (Панама), обладали яркой желтой биолюминесценцией. В статье сообщалось, что свет был непрерывным и не менялся как в процессе сбора образцов древесины, так и в течение суток. Авторы считали проведенное исследование уникальным, так как изучалась биолюминесценция светящегося гриба на его натуральном субстрате в отличие от изучения люминесценции грибов, культивируемых в лабораториях на искусственных питательных средах. Вид гриба остался неописанным, потому что не были обнаружены его плодовые тела.

В наших экспедиционных поисках светящихся грибов на острове Борнео в 2012-2013 годах на пнях кокосовых пальм и скорлупе сгнивших кокосов были обнаружены светящиеся плодовые тела двух видов. В то же время мы наблюдали свечение древесины и опавших листьев, на которых плодовые тела отсутствовали.

Данная статья посвящена исследованию образцов светящейся древесины кокосовой пальмы, собранных на острове Борнео. В ней сообщается о получении культуры грибного мицелия из образцов светящейся древесины и приведены результаты изучения люминесценции мицелия пока не идентифицированного гриба в условиях лабораторного культивирования.

\section{Материалы и методы}

Поиски объектов, светящихся в ночном лесу, проходили в окрестностях биостанции Северного Борнео (Nort Borneo Biostation [http://borneobiostation.com/ biostation/]), pacположенной в 12 км от г. Кудат (6 $6^{\circ} 53^{\prime} 1^{\prime \prime}$ с.ш. с.ш., 116 50'52" в.д.). Светящаяся древесина обнаружена в 2013 году в период с 25 ноября по 5 декабря. Свет исходил от лежащего на земле ствола кокосовой пальмы. Образцы светящейся древесины были вырублены из ствола и в полиэтиленовых пакетах привезены в Институт биофизики СО РАН (г. Красноярск - 56 $00^{\prime} 34^{\prime \prime}$ с.ш., 9247'30" в.Д.). Образцы древесины были помещены в термостат (ТСО$1 / 80$, СПУ, Россия) и климатическую камеру (WTH-E155, Daihan Scientific Co., Ltd., Корея). В термостате влажность не регулировалась и определялась испарением воды, налитой в полиэтиленовые пакеты, при температуре $27{ }^{\circ} \mathrm{C}$. Образцы в климатической камере находились при температуре $25^{\circ} \mathrm{C}$ и влажности $99,8 \%$.

Визуализацию люминесцентных областей образцов осуществляли с помощью компьютеризированной системы видеодокументации GelDoc XR Imaging System (BioRad Laboratories, Inc., США). Система предназначена для регистрации и исследования 
электрофорезных гелей, колоний на твердых питательных средах и других объектов и включает регистрационный бокс Universal Hood II, который экранирован от внешнего света и имеет встроенную высокочувствительную черно-белую цифровую камеру и собственные источники света. Образцы (древесина, чашки Петри или колбы с мицелием) помещали в регистрационный бокс. При включенном свете дневных ламп получали изображение образцов в видимом свете, при выключенных лампах регистрировали области образцов, обладающие люминесценцией. Условия регистрации люминесцентного сигнала следующие: диафрагма максимально открыта; время накопления сигнала до 300 с. При низком уровне люминесценции изображение усиливалось программным путем - функция Transform: gamma 4.00, low 0.0 (вариант А) или gamma 4.00, low 60021 (вариант Б).

Для получения чистой культуры мицелия с помощью системы видеодокументации были отобраны образцы древесины с высоким уровнем люминесценции, которые были промыты водой от остатков почвы. В условиях ламинара (Purifier ${ }^{\circledR}$ Biological Safety Cabinet, Labconco ${ }^{\circ}$, США) поверхность образцов была простерилизована на пламени спиртовки, древесина была расколота стерильным скальпелем и помещена в чашки Петри на пять твердых питательных сред разного состава (содержание агар-агара 15-20 г/л):

1) среда М (глюкоза - 2 г/л, мальт (солодовый) экстракт - 20 г/л, пептон - 1 г/л);

2) среда PD (картофельный экстракт 200 г/л, декстроза - 20 г/л);

3) среда ҮМ (дрожжевой экстракт - 3 г/л, мальт-экстракт - 3 г/л, глюкоза - 10 г/л, пептон -5 г/л);

4) среда YS (дрожжевой экстракт - 10 г/л, тростниковый сахар - 100 г/л);
5) среда С (микологический пептон 10 г/л, глюкоза - 40 г/л).

Готовые питательные среды или их компоненты получены от компании HiMedia Lab (Индия).

Использовали также два вида твердых питательных сред $\mathrm{C}$, заменяя воду на водную вытяжку из зерен пшеницы $(\mathrm{C}+3)$ или древесины, из которой получен мицелий $(\mathrm{C}+\Pi)$.

При культивировании на твердых питательных средах регистрацию свечения мицелия проводили непосредственно в чашках Петри диаметром 35 мм с помощью люминометра Glomax ${ }^{\circledR}$ 20/20 (Promega, США). Peгистрационный бокс люминометра предназначен для проведения измерений в чашках Петри и пробирках типа Эппендорф, например MCT-200-C (Axygen Scientific, Inc., США). Интенсивность световой эмиссии мицелия регистрировали в относительных единицах (URL) за $1 \mathrm{c}$.

Светящийся мицелий, выросший в чашках Петри и зарегистрированный в Коллекции культур ИБФ СО РАН под номером ИБСО 2371, являлся посевным материалом для получения культуры в жидкой питательной среде. Для этого биомассу выросшего мицелия отделяли от субстрата, протирали через металлическое сито (размер отверстий 2 × 2 мм) и помещали в колбу объемом 300 мл, содержащую 100 мл питательной жидкой среды PD. Культивирование проводили на шейкере-инкубаторе Мax Q 4000 (Thermo Scientific, США) при температуре $27-29{ }^{\circ} \mathrm{C}$ и постоянном перемешивании со скоростью 140 об/мин.

Пеллеты, выросшие в объеме жидкой питательной среды, использовали для изучения люминесценции мицелия. Для этого пробирки МСТ-200-С с помещенными в них пеллетами устанавливали в люминометр и регистрировали интенсивность люминесцентного сигнала до и после добавления 
растворов различных веществ. При измерении свечения каждая пробирка содержала 500 мкл деионизованной воды, в которую вносили по одной пеллете одинакового размера. Интенсивность световой эмиссии регистрировали в URL/c.

В качестве веществ, стимулирующих люминесценцию, использовали растворы $\mathrm{H}_{2} \mathrm{O}_{2}$ (Галено Фарм ${ }^{\mathrm{TM}}$, Россия) - финальная концентрация 8.8 мМ, НАДФН (Serva, Германия) - финальная концентрация 0.3 мМ и водный экстракт из плодовых тел несветящегося гриба Pholiota squarrosa (Oeder) Kumm. (чешуйчатка), растущих в окрестных лесах города Красноярска.

Для приготовления водного экстракта собранные в лесу плодовые тела P. squarrosa промывали в дистиллированной воде (для удаления загрязнений), нарезали на кусочки (для улучшения экстракции) и переносили в стеклянный термостойкий стакан. К биомассе добавляли дистиллированную воду в соотношении 1:4 (объем воды : объем сырой биомассы), образец помещали в СВЧ-печь (model MW 712BR, Samsung, Малайзия) и при мощности $800 \mathrm{~W}$ нагревали до закипания воды. После этого образец охлаждали на льду и центрифугировали при 20000 g в течение 30 мин при температуре $4{ }^{\circ} \mathrm{C}$ (Avanti® J-E centrifuge, Beckman-Coulter, США). Осадок отбрасывали, а супернатант замораживали при температуре минус $80{ }^{\circ} \mathrm{C}\left(-86^{\circ} \mathrm{C}\right.$ Ultralow Freezer, NuAire, Inc., США), лиофильно высушивали (сушилка лиофильная ЛС-500, Россия) и хранили при температуре минус $20^{\circ} \mathrm{C}$ до момента использования.

Для получения иллюстративного материала также применяли фотоаппарат Canon EOS 6D. При съемке образцов на свету использовали режим ISO 200-500, экспозиция 0.4-0.8 с. Съемку в темноте проводили в режиме ISO 1600-4000, экспозиция 45-90 с.

\section{Результаты и обсуждение}

Светямаяся древесина

Собранные на острове Борнео образцы светящейся древесины кокосовой пальмы, которые испускали зеленоватый свет, были в течение трех суток доставлены в лабораторию ИБФ СО РАН для дальнейшего изучения (рис. 1). Как показали исследования, при длительном хранении во влажных условиях на образцах светящейся древесины вырастают воздушные гифы мицелия, которые также обладают свечением. При этом было выявлено, что интенсивность люминесцентного сигнала не постоянная величина, так как наблюдаются «блуждающие» области с изменяющимся уровнем световой эмиссии (рис. 2).

Через 6 месяцев хранения на некоторых образцах древесины были обнаружены гифы мицелия, имеющие светящиеся шаровидные утолщения (рис. 3, 4). Эти образования наблюдались в течение примерно двух месяцев. Затем они редуцировались и в дальнейшем не появлялись. Высокий уровень люминесценции гиф и шаровидных образований позволял регистрировать их свечение не только на видеосистеме (рис. 3), но и с помощью фотоаппарата Canon EOS 6D (рис. 4).

На момент написания статьи свечение привезенных нами образцов древесины, регистрируемое с помощью видеосистемы, сохраняется уже в течение 24 месяцев. Это подтверждает сведения других авторов о том, что способность древесины светиться сохраняется длительное время (Sabharwal et al., 1983; Deheyn, Latz, 2007). Полученные данные свидетельствуют в пользу высокой жизнеспособности изучаемого мицелия и позволяют сделать некоторые выводы. Исходя из нашего опыта, для данных образцов светящейся древесины не обязательна их быстрая транспортировка в лабораторию и соблюдение стерильных условий. Однако важным фактором 


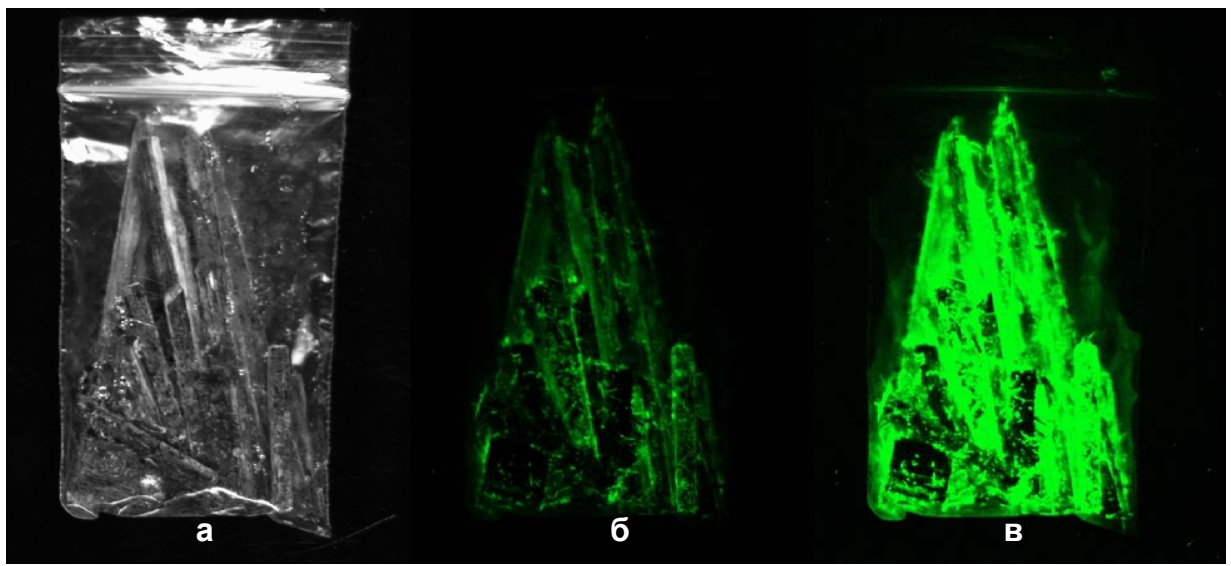

Рис. 1. Внешний вид образцов древесины в полиэтиленовом пакете (а) и их люминесценция (б, в). Регистрация изображения с помощью GelDoc XR Imaging System. Режим: б - время накопления 300 с (вариант А); в - время накопления 300 с (вариант Б)
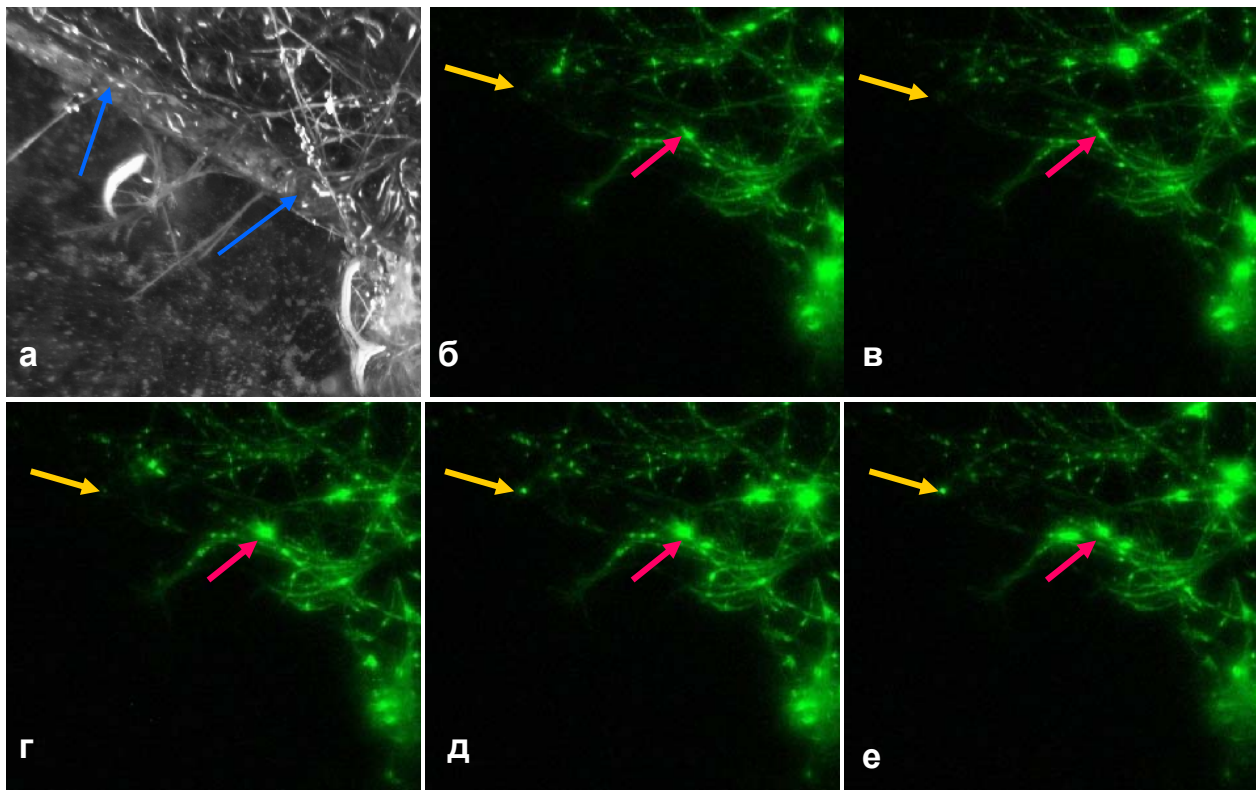

Рис. 2. Внешний вид образца (а) и люминесценция воздушного мицелия (б-е), выросшего при хранении древесины во влажных условиях. Регистрация изображения GelDoc XR Imaging System с интервалом через 5 мин. Режим: время накопления 300 с (вариант Б) (снято 15 октября 2015 года, древесина собрана 5 декабря 2013 года). Синие стрелки - образец древесины, желтые и красные стрелки - области мицелия, изменяющие интенсивность люминесценции

является поддержание высокой влажности. По нашим наблюдениям, при уменьшении влажности древесины интенсивность ее свечения снижалась до уровня, который не регистрировался ни видеосистемой, ни люминометром. Как показали исследования, дальнейшее уве- личение влажности таких образцов не приводит к восстановлению их свечения, а на поверхности древесины начинают прорастать низшие грибы. Таким образом, основным условием для длительного сохранения световой эмиссии древесины является наличие 


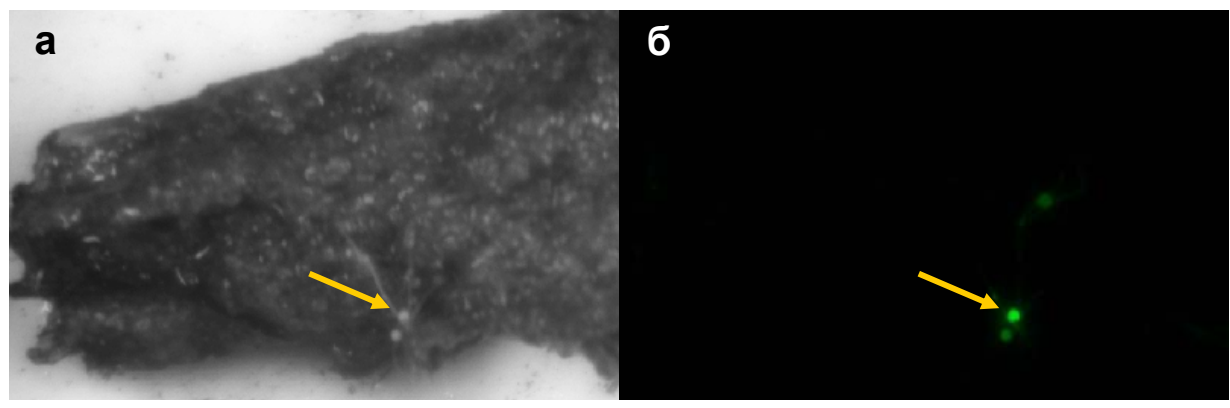

Рис. 3. Внешний вид (а) и люминесценция (б) шаровидных образований (указаны стрелкой) на гифах воздушного мицелия. Регистрация изображений на GelDoc XR Imaging System, режим: время накопления 30 с (вариант А)

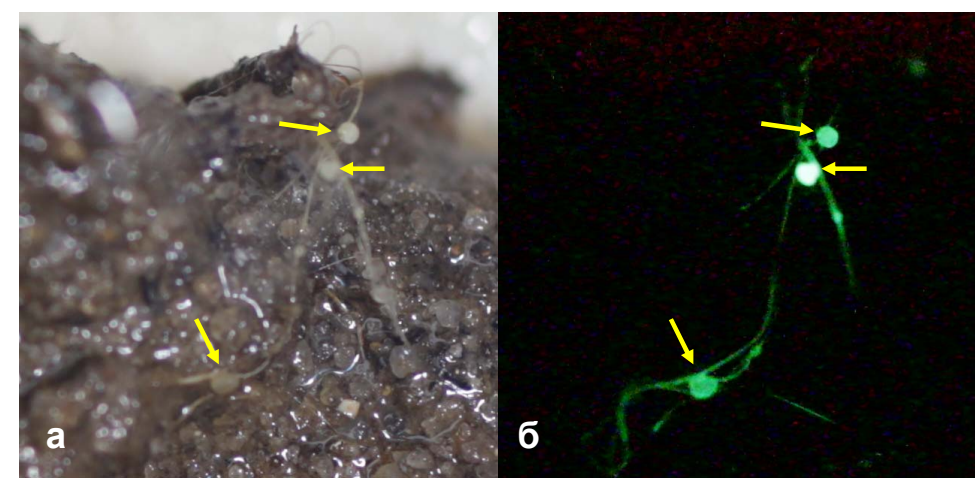

Рис. 4. Внешний вид при дневном освещении (а) и свечение в темноте (б) воздушных гиф мицелия с шаровидными образованиями (указаны стрелками), выросших при хранении образца древесины во влажных условиях. Регистрация изображений фотоаппаратом Canon EOS 6D. Режимы: a - AE, ISO 400, экспозиция 0.8 c; б - AE, ISO 4000, экспозиция 45 с

влаги. При длительном хранении во влажных условиях не только поддерживается жизнедеятельность уже имеющегося субстратного мицелия, но и развивается воздушный мицелий, обладающий свечением (рис. 2-4).

Поскольку образцы древесины находятся в нестерильных условиях, а на их поверхности не наблюдается роста низших грибов и бактерий, можно предположить, что светящийся мицелий обладает бактериостатическими свойствами, угнетая развитие микрофлоры. Необходимо отметить, что нам не удалось получить чистую культуру при использовании в качестве посевного материала светящийся воздушный мицелий, выросший на поверхности древесины при ее хранении в лаборатор- ных условиях. При инокуляции воздушного мицелия на твердые питательные среды и последующем культивировании на поверхности агара наблюдался рост только колоний бактерий и низших грибов. Возможно, это связано с различием в составе питательных компонентов, которые мицелий использует для роста на искусственных средах или на естественном субстрате тропического леса. Древесина кокосовой пальмы является бедным питательным субстратом, и расти на ней способны не все организмы. Поэтому когда в естественных условиях тропического леса изучаемый нами мицелий смог колонизировать (развиться, захватить) природный древесный субстрат, при дальнейшем росте он 
способен угнетать рост сопутствующей микрофлоры. Вероятно, при попадании в условия богатой питательной среды сопутствующая микрофлора (низшие грибы и бактерии), обладающая большей скоростью роста, имеет преимущество и подавляет тем самым рост гриба, не позволяя получить чистую культуру светящегося мицелия.

За 24 месяца наблюдений визуально не обнаружено каких-либо изменений в размеpax, форме или цвете образцов светящейся древесины. Это позволяет сделать два предположения. Первое - естественный субстрат содержит достаточное количество питательных веществ, обеспечивающих жизнеспособность и светоизлучение гриба при поддержании определенной температуры и влажности в течение длительного (годы) периода времени. Второе - мицелий гриба не является основным фактором, вызывающим быстрое разрушение древесины.

\section{Светящчийся мицелий:}

получение чистой культуры,

особенности люминесценции

при культивировании

на твердых питательных средах

Для получения чистой культуры мицелия были использованы твердые питательные среды разного состава. С помощью видеосистемы вначале была определена локализация светящихся областей образцов древесины (рис. 5). Из этих областей были вырезаны фрагменты для посева на агаризованные питательные среды. Затем сравнение и анализ изображений, полученных в видимом свете и в темноте, позволяли классифицировать и отбирать ярко светящиеся кусочки древесины, помещенные на питательную среду (рис. 6), а впоследствии - контролировать рост и свечение мицелия (рис. 7). Информация о питательных средах и времени культивирования мицелия на чашках, показанных на рис. 7, представлена в табл. 1.

Как показали исследования, чистую культуру мицелия изучаемого гриба можно получить, если в качестве посевного материала использовать внутренние слои древесины, которые пронизаны светящимся мицелием, но не содержат присутствующих на поверхности микроорганизмов и их спор. При этом видеосистема существенно облегчает микробиологические работы по получению культуры грибного мицелия из древесины. Анализ полученных изображений позволяет локализовать (определить) участки, обладающие максимальным свечением (рис. 5). Мы предполагаем, что причинами высокой интенсивности люминесценции могут быть большое количество гиф гриба на единицу площади природной древесины и высокий жизненный потенциал растущего мицелия (интенсивность его метаболизма). Использование такого посевного материала позволяет с большей вероятностью получить рост мицелия гриба на питательных средах.

Визуализация внесенных на агаризованные питательные среды кусочков древесины, обладающих свечением, дала возможность отобрать чашки Петри с высоким уровнем световой эмиссии посевного материала (рис. 6) и проследить рост колоний мицелия и развитие его люминесценции на разных питательных средах (рис. 7). При этом люминесцентные сигналы, регистрируемые от мицелия, являлись доказательством роста именно светящегося гриба, а не случайной контаминации. Последующий пересев выросшего мицелия, обладающего свечением на средах различного состава, позволил получить стабильную культуру гриба - изолят ИБСО 2371.

При выращивании культуры гриба ИБСО 2371 на твердых питательных средах разного состава были обнаружены различия в ско- 


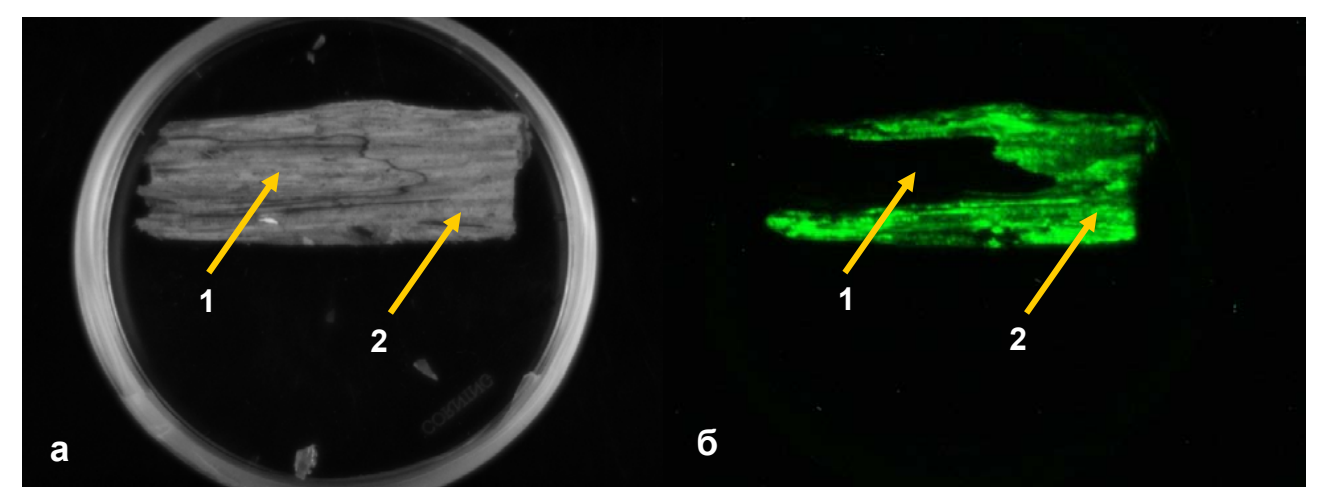

Рис. 5. Внешний вид (а) и области свечения (б) образца древесины, предназначенного для получения посевного материала. Регистрация изображений системой GelDoc XR Imaging System, режим: время накопления 300 с (вариант A). Стрелками показаны: 1 - участок несветящейся древесины; 2 - участок светящейся древесины

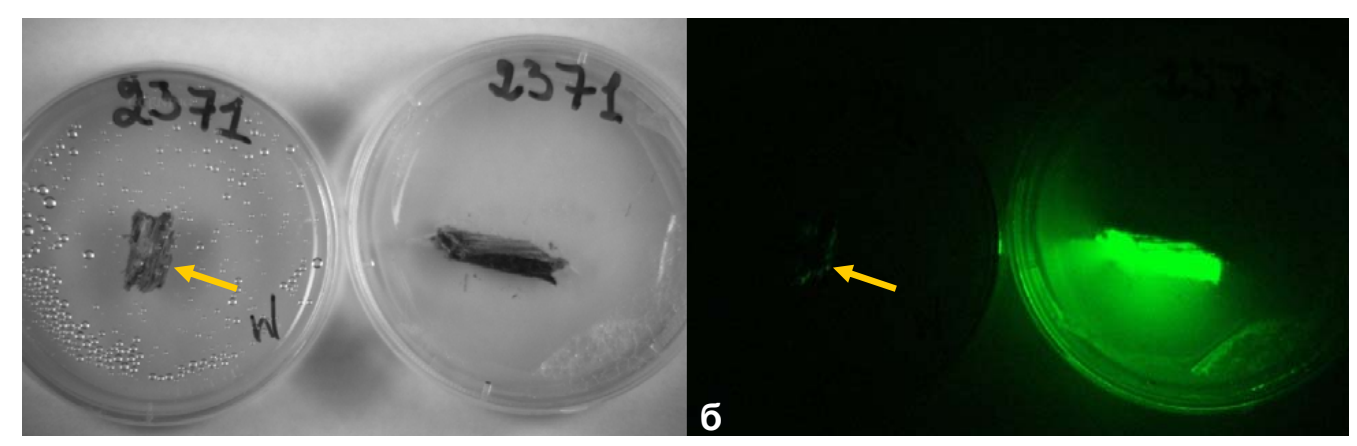

Рис. 6. Внешний вид (а) и свечение (б) образцов древесины, помещенных на питательную среду М в чашках Петри диаметром 60 мм. Регистрация изображений с помощью GelDoc XR Imaging System, режим: время накопления - 300 с (вариант Б). Стрелкой указан образец древесины, не обладающей свечением

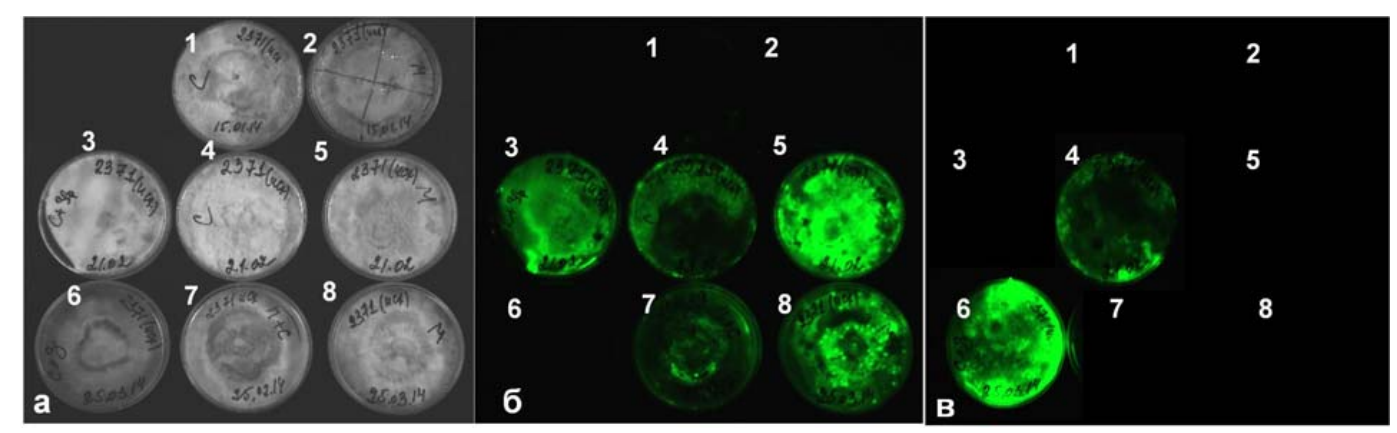

Рис. 7. Внешний вид (а) и люминесценция $(б$, в) мицелия на разных питательных средах. Регистрация изображения системой GelDoc XR Imaging System. Режим - время накопления 300 с (вариант A). Информация о питательных средах и времени культивирования представлена в табл. 1 
Таблица 1. Состав питательных сред и время культивирования гриба (сутки) в чашках Петри, показанных на рис. 7

\begin{tabular}{|c|c|c|c|}
\hline \multirow{3}{*}{ Рис. 7а и $7 б$} & & № 1, среда С, 112 сут & № 2, среда M, 112 сут \\
\hline & №3, среда С+3, 72 сут & № 4, среда С, 72 сут & №5, среда М, 72 сут \\
\hline & №6, среда С+3, 68 сут & № 7, среда С+П, 68 сут & №8, среда М, 39 сут \\
\hline \multirow{3}{*}{ Рис. 7в } & & № 1, среда С, 216 сут & № 2, среда M, 216 сут \\
\hline & №3, среда C+3, 176 сут & № 4, среда С, 176 сут & №5, среда М, 176 сут \\
\hline & №6, среда C+3, 172 сут & № 7, среда $\mathrm{C}+\Pi, 172$ сут & №8, среда М, 143 сут \\
\hline
\end{tabular}

ростях роста мицелия и интенсивности его свечения. Было показано, что мицелий лучше растет и обладает большей интенсивностью световой эмиссии при культивировании на средах М и ҮM, содержащих солодовый экстракт, и среде С. При культивировании на среде $\mathrm{PD}$ мицелий рос медленнее и уровень его свечения был ниже, чем при выращивании на среде M. На среде YS, содержащей дрожжевой экстракт и сахарозу, скорость роста мицелия была наименьшей по сравнению с другими использованными средами. На рис. 7 представлены изображения мицелия при разном времени его культивирования в чашках Петри на средах разного состава. Регистрация интенсивности люминесценции этих образцов с помощью люминометра свидетельствует о том, что яркое свечение (более 5 x $10^{6} \mathrm{RLU} / \mathrm{c}$ ), наблюдаемое в темноте визуально, начинается на 20-40-й день роста мицелия. Было показано, что максимум свечения образцов мицелия (до 2.9 х $10^{8} \mathrm{RLU} / \mathrm{c}$ ) регистрируется на 80-100-й день роста, затем оно постепенно угасает, тем не менее, оставаясь в течение длительного времени (до 140 сут и более) на достаточно высоком уровне (до 4-5 х 106 RLU/c). При этом были выявлены временные различия в изменениях интенсивности свечения мицелия, выращиваемого на средах М и С. Так, при культивировании мицелия на среде М его свечение на уровне $10^{6}$ RLU/c наблюдалось раньше (на 2-5 суток), чем у мицелия, который выращивали на среде С. На среде М максимум свечения мицелия тоже наблюдался в более ранние сроки (49100-е сутки культивирования) по сравнению с максимумом свечения мицелия на среде $\mathrm{C}$ (85-104-е сутки культивирования). Угасание свечения мицелия на среде М также происходило раньше, чем на среде $\mathrm{C},-$ на 102-е и 113-е сутки соответственно. В дополнительных исследованиях было обнаружено, что замена воды в среде С на водный экстракт из древесины кокосовой пальмы (среда $\mathrm{C}+$ П) позволяет увеличить продолжительность свечения мицелия до 150 суток, максимум которого наблюдался на 100-120-е сутки. При этом было установлено, что замена воды в среде С водным экстрактом из зерен пшеницы (среда $\mathrm{C}+3)$ позволяет не только значительно (более 170 суток) увеличить продолжительность световой эмиссии мицелия, но и расширить временной период (34-149 суток) его максимально яркого свечения (4.9-7.4 х 107 RLU/c). Совокупность этих данных дает возможность утверждать, что длительность и интенсивность люминесценции изучаемого мицелия в значительной степени зависят от состава питательной среды, на которой он культивируется.

Следует отметить, что при анализе изображений люминесценции мицелия на твердой питательной среде было установлено наличие «блуждающих» областей свечения 

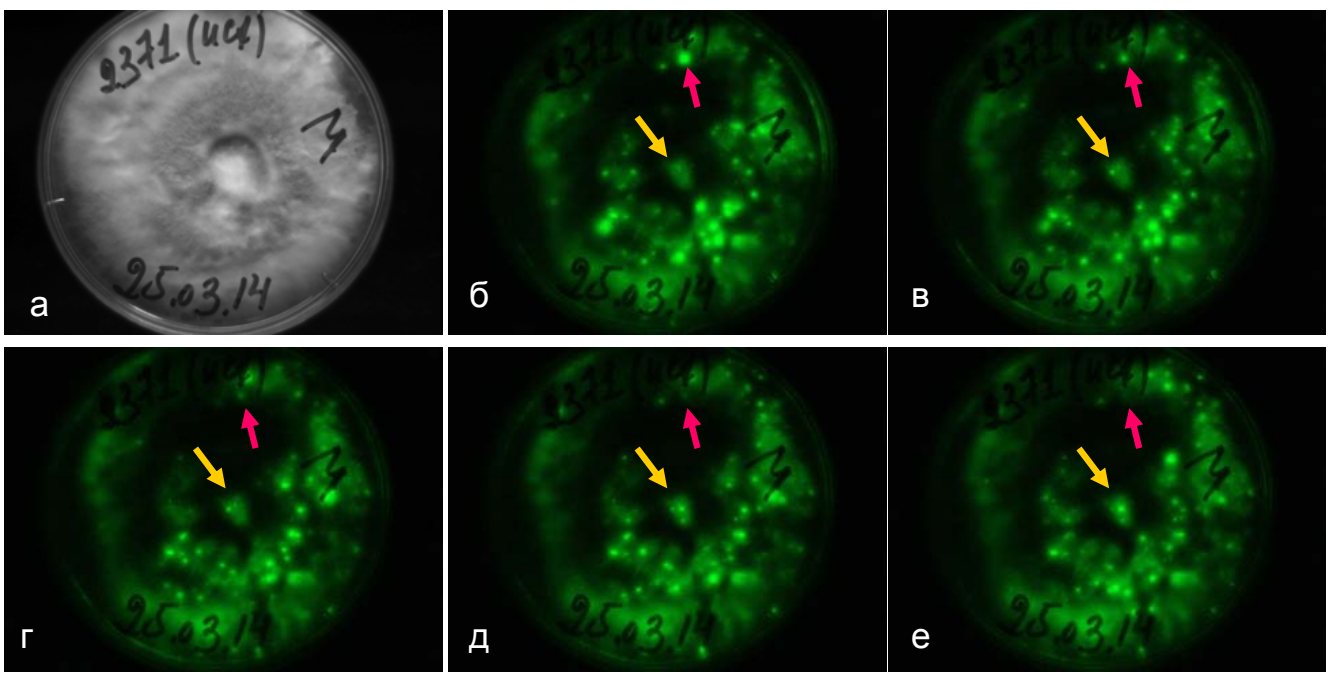

Рис. 8. Внешний вид чашки Петри с 36-суточным мицелием (а) и «блуждающие» области с меняющимся уровнем люминесценции (б - e). Регистрация изображения GelDoc XR Imaging System с интервалом через 5 мин. Режим: время накопления 60 с (вариант Б). Красная стрелка - уменьшение интенсивности свечения, желтая - возрастание интенсивности свечения

с меняющимся уровнем световой эмиссии (рис. 8, дополнительные данные (видео) на сайте http://bl.ibp.ru/index.php?module=subje cts\&func=viewpage\&pageid=169), подобных наблюдаемым при исследовании воздушного мицелия на образцах древесины (рис. 2). Причины данного феномена пока непонятны и требуют дальнейшего изучения.

Отличительными особенностями изучаемой культуры, растущей на твердых питательных средах, по отношению к другим культурам исследованных нами светящихся грибов (Medvedeva et al., 2014) являются:

- низкая скорость роста мицелия - одна из самых медленных для всех культур люминесцентных грибов, культивируемых в ИБФ СО РАН (Panellus stipticus, Mycena citricolor, Lampteromyces japonicus, Neonothopanus nambi, Armillaria - 37 изолятов);

- длительное время свечения мицелия - 150 суток и более, с интенсивностью световой эмиссии до 4-5 х $10^{6}$ RLU/c. При этом максимальная интенсивность свечения изучаемого мицелия может достигать значений 2.9-5.0 × $10^{8} \mathrm{RLU} / \mathrm{c}$, что сравнимо с интенсивностью свечения мицелия известных базидиомицетов;

- наличие при росте гиф на древесине и твердой питательной среде локальных областей с высоким уровнем люминесценции, которые изменяют интенсивность свечения за короткое время, создавая эффект появления, перемещения и исчезновения светящихся областей.

\section{Светящчийся мицелий.}

культивирование в жидкой

питательной среде

При культивировании гриба в жидкой питательной среде рост мицелия ИБСО 2371 наблюдается в виде пеллет (глобул) шарообразной формы, имеющих значительное количество длинных выростов, расположенных по всей поверхности. Типичный внешний вид пеллет представлен на рис. 9. Следует отме- 
тить, что при росте культуры мицелия в объеме жидкой питательной среды невозможно получить изображение светящихся пеллет с помощью видеосистемы, так как для них характерен сигнал до $100 \mathrm{RLU} / \mathrm{c}$ (рис. 10), который регистрируется на высокочувствительном люминометре и близок к уровню фонового шума прибора. Таким образом, это редкое

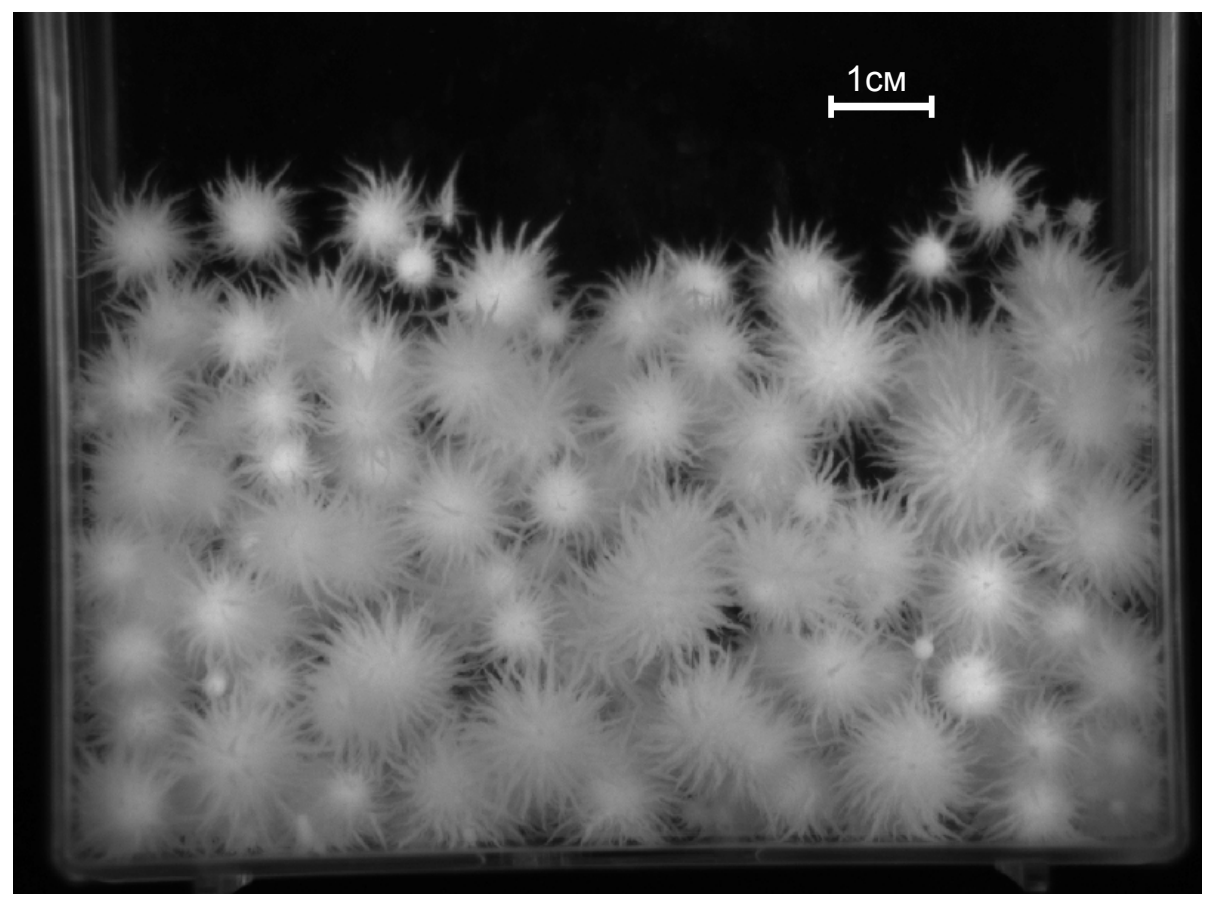

Рис. 9. Внешний вид пеллет, полученных при глубинном культивировании мицелия гриба. Регистрация изображения на GelDoc XR Imaging System в режиме дневного освещения

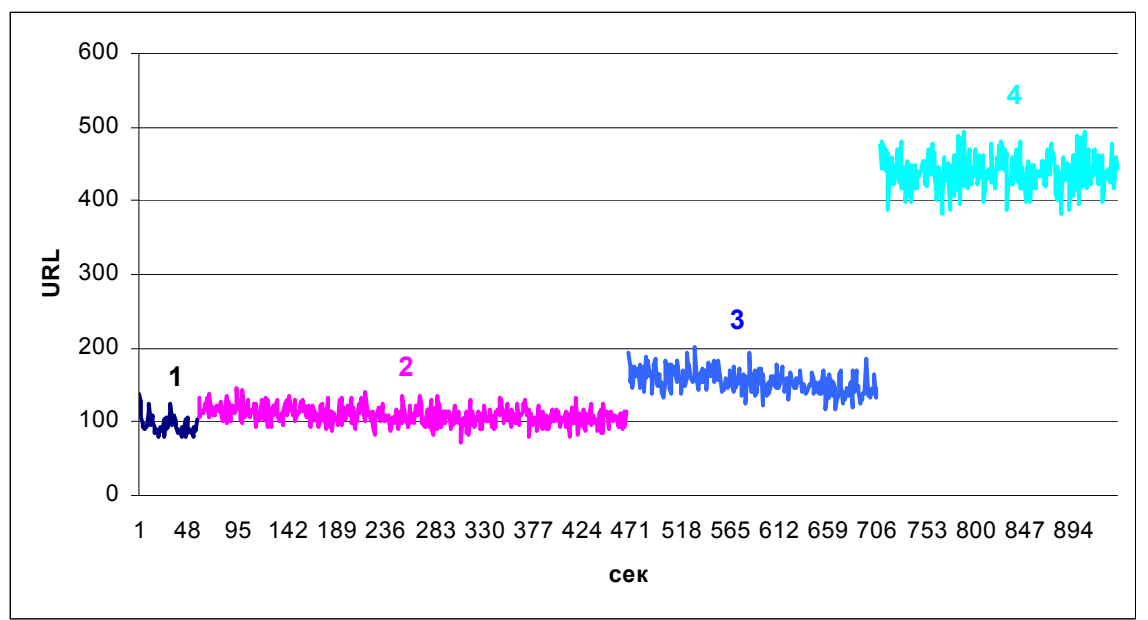

Рис. 10. Типичные световые сигналы пеллет мицелия изучаемого гриба в питательной среде: собственное свечение (1), после добавления 5 мкл экстракта из гриба $P$. squarrosa и перемешивания (2), после добавления 5 мкл НАДФН и перемешивания (3), после добавления 5 мкл перекиси и перемешивания (4). Регистрация - Glomax® 20/20 
явление, так как в литературе описан только один подобный случай, когда при росте на твердой питательной среде мицелий светоизлучающего базидиомицета Panellus stipticus обладал визуально видимым в темноте свечением, а при росте в жидкой питательной среде утрачивал эту способность (Bermudes et al., 1990).

Существуют два методических приема, позволяющих значительно (от нескольких раз до порядков) увеличить интенсивность люминесценции мицелия, которые были использованы в данных исследованиях.

Первый - отмывка мицелия водой от остатков питательной среды и экзометаболитов (Mori et al., 2011; Bondar et al., 2012, 2013). Согласно приведенным данным (рис. 11, 12), инкубация пеллет мицелия изучаемого гриба в деионизованной воде в течение суток привела к появлению люминесценции, регистрируемой на уровне $10^{4}-10^{5} \mathrm{RLU} / \mathrm{c}$. При этом интенсивность световой эмиссии пеллет возрастала при механическом воздействии, что считается характерным откликом для мицелия светящихся базидиомицетов.
Второй - внесение веществ, увеличивающих люминесцентный сигнал. К таким веществам можно отнести $\mathrm{H}_{2} \mathrm{O}_{2}$, а также водный экстракт P. squarrosa и НАДФН. Применение этих веществ в данной работе основывалось на следующих установленных ранее фактах. Известно, что пероксид водорода стимулирует как световую эмиссию мицелия светоизлучающего гриба Neonothopanus nambi, так и люминесцентную систему, выделенную из мицелия этого гриба (Bondar et al., 2011, 2014). Для восстановленных пиридиновых нуклеотидов и водного экстракта $P$. squarrosa известно, что они увеличивают световые сигналы люминесцентных систем, выделенных из мицелия светящихся грибов (Airth, McElroy, 1959; Shimomura, 2006; Oliveira et al., 2012; Purtov et al., 2015). Можно было предполагать, что перечисленные вещества будут стимулировать и свечение пеллет мицелия изучаемого нами гриба.

Люминесцентные сигналы пеллет, кинетика и уровень световой эмиссии при последовательном добавлении растворов НАДФН, пероксида водорода и экстракта из плодо-

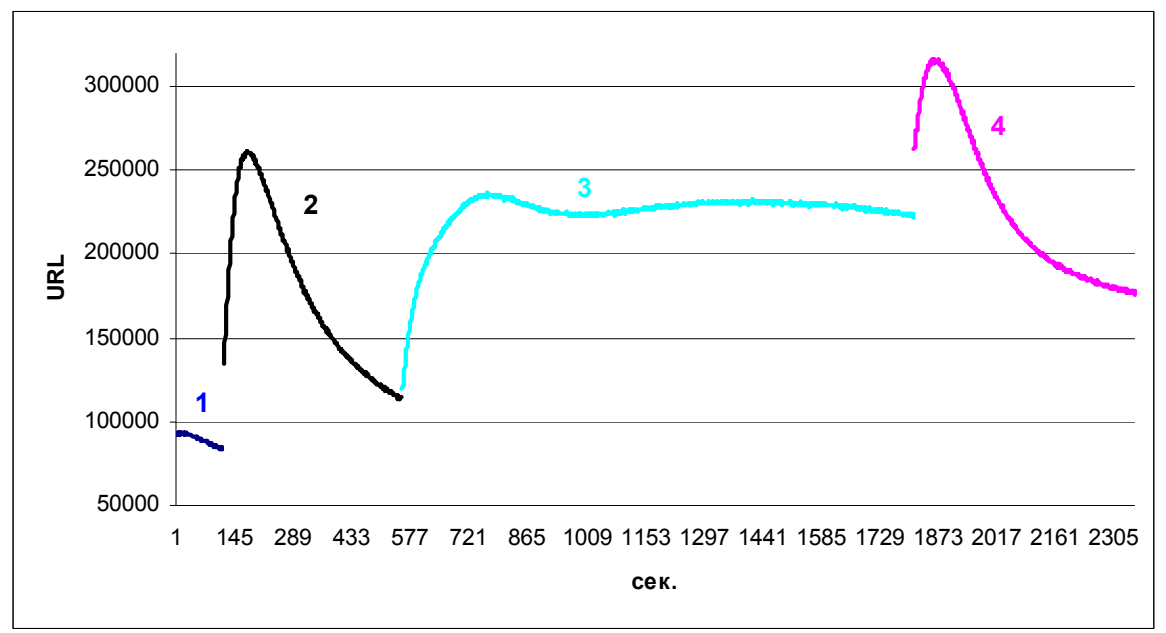

Рис. 11. Световые сигналы пеллеты мицелия изучаемого гриба после инкубации в деионизованной воде в течение суток: собственное свечение (1), реакция на перемешивание (2), реакция на добавление 5 мкл перекиси и перемешивание (3), реакция на добавление 5 мкл экстракта из гриба P. squarrosa и перемешивание (4). Регистрация - Glomax ${ }^{\circledR}$ 20/20 


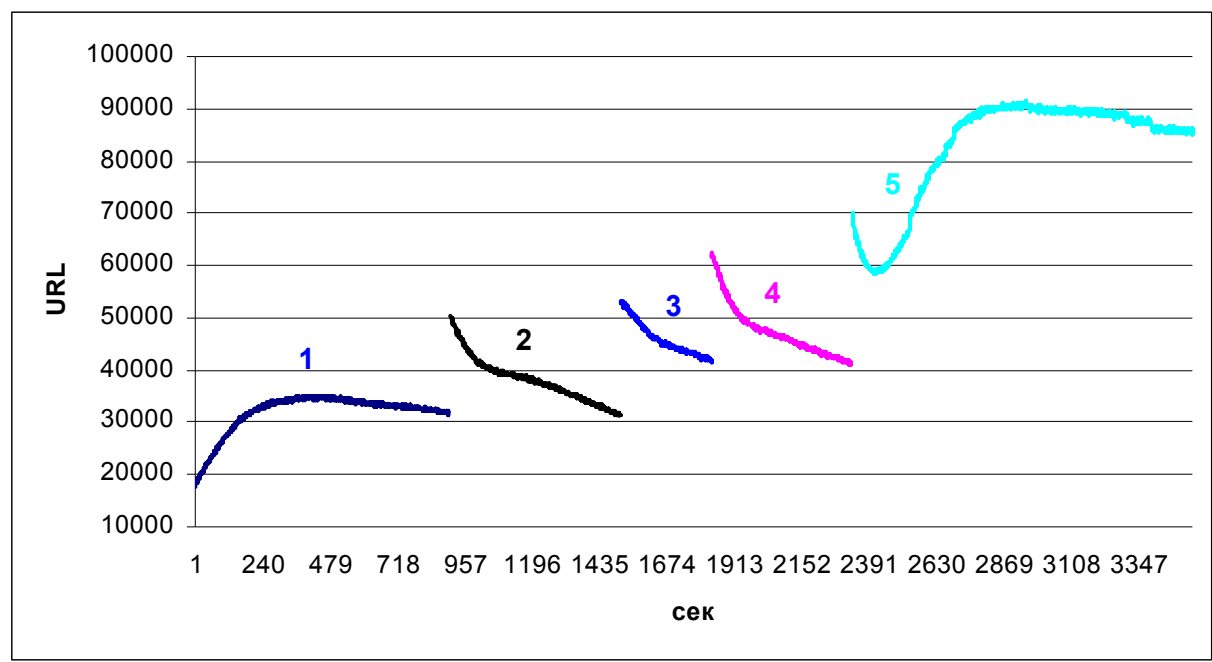

Рис. 12. Световые сигналы пеллеты мицелия изучаемого гриба после инкубации в деионизованной воде в течение суток: собственное свечение (1), реакция на перемешивание (2), реакция на добавление 5 мкл НАДФН и перемешивание (3), реакция на добавление 5 мкл экстракта из гриба P. squarrosa и перемешивание (4), реакция на добавление 5 мкл перекиси и перемешивание (5). Регистрация - Glomax ${ }^{\circledR}$ $20 / 20$

вых тел гриба P. squarrosa представлены на рис. 10-12. Была установлена принципиальная разница между интенсивностью люминесценции пеллет, извлеченных из питательной среды (рис. 10) сразу после культивирования гриба, и уровнем световой эмиссии пеллет, которые 24 ч находились в деионизованной воде при постоянном барботировании воздухом (рис. 11, 12).

Как показали измерения (рис. 10), мицелий, извлеченный из питательной среды, не обладал свечением и практически не реагировал на механическое воздействие, а также на добавки экстракта из плодовых тел гриба P. squarrosa и НАДФН. Люминесценция крайне низкой интенсивности (не более 400450 RLU/c) наблюдалась при добавках к пеллетам пероксида водорода.

Кроме того, необходимо отметить, что отдельная пеллета имеет индивидуальные характеристики в уровне исходной световой эмиссии и динамике изменений свечения при воздействии изучаемых факторов (ме- ханическое раздражение при перемешивании пробы, добавка растворов веществ). Из представленных примеров (рис. 11, 12) видно, что различия в интенсивности свечения отдельных пеллет могут быть значительными. Так, начальная величина люминесценции одной из пеллет (рис. 11) составляла около $10^{5} \mathrm{RLU} / \mathrm{c}$ и незначительно снижалась в дальнейшем. В то же время начальный уровень свечения другой пеллеты (рис. 12) не превышал значений 1.8 х $10^{4}$ RLU/c и возрастал со временем. Механическое воздействие, вызываемое перемешиванием, сопровождается индивидуальным изменением световой эмиссии. Причиной увеличения люминесценции при перемешивании может являться как механическое раздражение, так и увеличение концентрации кислорода в объеме среды, содержащей образец. Такой эффект, например, характерен для мицелия светящегося гриба N. nambi (Bondar et al., 2013) и светящихся бактерий (Гительзон и др., 1984). 
Несмотря на упомянутые выше существенные индивидуальные различия в начальной интенсивности свечения разных пеллет, можно говорить и об однотипных особенностях динамики их люминесценции в ответ на воздействие внешнего фактора (факторов). Например, характерны для пеллет после инкубации в воде: повышение уровня люминесценции при добавлении $\mathrm{H}_{2} \mathrm{O}_{2}$ и сохранение повышенного уровня световой эмиссии в течение длительного времени; отсутствие существенных изменений люминесцентного сигнала при добавлении НАДФН. Стимулирующий эффект пероксида водорода, повидимому, может быть связан с вовлечением активных радикалов кислорода в механизм свечения изучаемого гриба. Это предположение представляется правомочным, поскольку участие активных форм кислорода и оксидазных ферментов в механизме светоизлучения высших грибов рассматривалось ранее в ряде работ (Shimomura, 1992; Shimomura et al., 1993; Shimomura, 2006; Bondar et al., 2011, 2012; Kobzeva et al., 2014).

Общей особенностью для пеллет мицелия изучаемого гриба является быстрая ответная реакция на воздействие внешнего фактора, включая добавку экстракта из плодовых тел несветящегося базидиомицета P. squarrosa, которая сопровождается практически мгновенным увеличением световой эмиссии. Наблюдаемые эффекты позволяют высказать следующее предположение. Вероятно, изначальное отсутствие свечения пеллет может быть связано с ингибированием ферментов светоизлучающей системы метаболитами, образующимися при глубинном способе культивирования изучаемого гриба, либо крайне низким содержанием в мицелии субстрата люминесцентной реакции. В пользу такого предположения свидетельствует то, что инкубация пеллет в деионизованной воде и барботаж воздухом приводят к появлению люминесценции у мицелия, а добавка экстракта из гриба P. squarrosa сопровождается повышением уровня его световой эмиссии.

\section{Заключение}

Таким образом, из образцов светящейся древесины получена чистая культура пока не идентифицированного вида светящегося гриба. Контроль люминесценции и отбор светящихся образцов впервые проводили с помощью системы видеодокументации GelDoc XR Imaging System (Bio-Rad Laboratories, Inc., USA). Согласно представленным данным, такой подход эффективен для получения культуры мицелия светоизлучающего высшего гриба, если не удается обнаружить его плодовые тела в естественных (природных) условиях обитания. Наличие чистой культуры мицелия открывает возможность таксономической идентификации обнаруженного вида гриба с использованием филогенетического анализа. Установлено, что мицелий ИБСО 2371 при росте на твердых питательных средах обладает продолжительным ярким свечением, уровень которого зависит от состава используемой среды. Отличительными особенностями изучаемой культуры являются: (а) наличие локальных областей, меняющих интенсивность свечения мицелия в течение коротких промежутков времени (несколько минут) при росте на твердых питательных средах или природной древесине; (б) отсутствие биолюминесценции при глубинном способе культивирования.

\section{Благодарности}

Авторы признательны профессору A.M. Франку, директору North Borneo Biostation, за возможность работы на биостанции.

Исследования выполнены при частичной финансовой поддержке за счет средств: 
государственного задания на проведение фундаментальных исследований РАН (проект № 0360-2014-0006), Программы Правитель- ства РФ «О мерах по привлечению ведущих ученых в учебные заведения России» (грант № 11.G34.31.0058), СО РАН (проект № 71).

\section{Список литературы}

Гительзон И.И., Родичева Э.К., Медведева С.Е., Примакова Г.А., Барцев С.И., Кратасюк Г.А., Петушков В.Н., Межевикин В.В., Высоцкий Е.С., Заворуев В.В., Кратасюк В.А. (1984) Светящиеся бактерии. Новосибирск, Наука, 277 с. [Gitelson J.I., Rodicheva E.K., Medvedeva S.E., Primakova G.A., Bartsev S.I., Kratasyuk G.A., Petushkov V.N., Mezhevikin V.V., Vysotski E.S., Zavoruev V.V., Kratasyuk V.A. (1984) Luminous bacteria. Novosibirsk, Nauka, 277 p. (in Russian)]

Ячевский А.А. (1933) Основы микологии. М. - Л., Сельхозгиз, 1036 с. [Yachevsky А.А. (1933) Fundamentals of mycology. Moscow-Leningrad, Selkhozgiz, 1036 p. (in Russian)]

Airth R.L., McElroy W.D. (1959) Light emission from extracts of luminous fungi. J. Bacteriol., 77: 249-250

Bermudes D., Gerlach V.L., Nealson K.H. (1990) Effects of culture conditions on mycelial growth and luminescence in Panellus stipticus. Mycologia, 82: 295-305

Bondar V.S., Puzyr A.P., Purtov K.V., Medvedeva S.E., Rodicheva E.K., Gitelson J.I. (2011) The luminescent system of the luminous fungus Neonothopanus nambi. Doklady Biochemistry and Biophysics, 438: 138-140

Bondar V.S., Shimomura O., Gitelson J.I. (2012) Luminescence of higher mushrooms. J. Sib. Fed. Univ., Biol., 5: 331-351

Bondar V.S., Rodicheva E.K., Medvedeva S.E., Tyulkova N.A., Tyaglik A.B., Shpak B.A., Gitelson J.I. (2013) On the mechanism of luminescence of the fungus Neonothopanus nambi. Doklady Biochemistry and Biophysics, 449: 80-83

Bondar V.S., Puzyr A.P., Purtov K.V., Petunin A.I., Burov A.E., Rodicheva E.K., Medvedeva S.E., Shpak B.A., Tyaglik A.B., Shimomura O., Gitelson J.I. (2014) Isolation of luminescence system from the luminescent fungus Neonothopanus nimbi. Doklady Biochemistry and Biophysics, 455: 56-58.

Deheyn D.D., Latz M.I. (2007) Bioluminescence characteristics of a tropical terrestrial fungus (Basidiomycetes). Luminescence, 22: 462-467

Kobzeva T.V., Melnikov A.R., Karogodina T.Y., Zikirin S.B., Stass D.V., Molin Yu.N., Rodicheva E.K., Medvedeva S.E., Puzyr A.P., Burov A.E., Bondar V.S., Gitelson J.I. (2014) Stimulation of luminescence of mycelium of luminous fungus Neonothopanus nambi by ionizing radiation. Luminescence, 29: 703-710

Medvedeva S.E., Artemenko K.S., Krivosheenko A.A., Rusinova A.G., Rodicheva E.K., Puzyr A.P., Bondar V.S. (2014) Growth and light emission of luminous basidiomycetes cultivated on solid media and in submerged culture. Mycosphere, 5: 565-577

Mori K., Kojima S., Maki S., Hirano T., Niwa H. (2011) Bioluminescence characteristics of the fruiting body of Mycena chlorophos. Luminescence, 26: 604-610

Oliveira A.G., Desjardin D.E., Perry B.A., Stevani C.V. (2012) Evidence that a single bioluminescent system is shared by all known bioluminescent fungal lineages. Photochem. Photobiol. Sci., 11: 848852

$$
-319-
$$


Purtov K.V., Petushkov V.N., Baranov M.S., Mineev K.S., Rodionova N.S., Kaskova Z.M., Tsarkova A.S., Petunin A.I., Bondar V.S., Rodicheva E.K., Medvedeva S.E., Oba Yuichi, Oba Yumiko, Arseniev A.S., Lukyanov S., Gitelson J.I., Yampolsky I.V. (2015) The chemical basis of fungal bioluminescence. Angew. Chem. Int. Ed., 54: 8124-8128

Sabharwal S.C., Kathuria S.P., Dhingra M.M. (1983) A new bioluminescent fungal system. J. Biosci., 5: 53-62

Shimomura O. (1992) The role of superoxide dismutase in regulating the light emission of luminescent fungi. Exp. Botany., 43: 1519-1525

Shimomura O. (2006) Bioluminescence: chemical principles and methods. Singapore, World Scientifc Publishing Co. Pte. Ltd., $470 \mathrm{p}$

Shimomura O., Satoh S., Kishi Y. (1993) Structure and nonenzymatic light emission of two luciferin precursors isolated from the luminous mushroom Panellus stipticus. J. Biolum. Chemilum., 8: $201-205$ 